\title{
вмJ Global Health Communicating COVID-19 vaccines: lessons from the dengue vaccine controversy in the Philippines
}

\author{
Gideon Lasco (D) , ,2 Vincen Gregory $\mathrm{Yu}^{2}$
}

To cite: Lasco G, Yu VG. Communicating COVID-19 vaccines: lessons from the dengue vaccine controversy in the Philippines. BMJ Global Health

2021;6:e005422. doi:10.1136/ bmjgh-2021-005422

Handling editor Seye Abimbola

Received 17 February 2021 Revised 19 February 2021 Accepted 20 February 2021

Check for updates

(C) Author(s) (or their employer(s)) 2021. Re-use permitted under CC BY-NC. No commercial re-use. See rights and permissions. Published by BMJ.

${ }^{1}$ Department of Anthropology, University of the Philippines Diliman, Quezon City, Philippines ${ }^{2}$ Development Studies Program, Ateneo de Manila University, Quezon City, Philippines

Correspondence to

Dr Gideon Lasco;

pdlasco@up.edu.ph

\section{INTRODUCTION: THE DENGUE VACCINE CONTROVERSY}

In 2016, the Philippines embarked on an unprecedented mass immunisation campaign against dengue fever, becoming the first Asian nation to authorise the commercial use of Dengvaxia, the dengue vaccine manufactured by the French pharmaceutical Sanofi Pasteur. ${ }^{1}$ In December 2017, nearly 2years since the campaign started, Sanofi announced that Dengvaxia may actually cause 'more severe disease' in those who have not had previous dengue infection. ${ }^{2}$ By then, over 800,000 Filipino schoolchildren had been inoculated. ${ }^{1}$

Criminal investigations against involved government figures ensued, with one critic likening the mass vaccination programme to a 'genocide against Filipino children'. ${ }^{3}$ The deaths of several children who had received the vaccine became a focal point of the scandal, as the Public Attorney's Office ran a highly publicised and dramatised investigation, from televised autopsies to the chief lawyer appearing alongside the grieving mothers in media interviews. ${ }^{3-5}$ The resulting 'crisis of confidence' against the public health sector sent immunisation rates plummeting to an all-time low, precipitating a measles outbreak across the country, exacerbating already-low immunisation rates. ${ }^{5}$

What went wrong, and how could a different-or more deliberate-communications strategy have contributed to averting those mistakes? In this article, we identify several lessons on health communication from the dengue vaccine controversy that may prove beneficial in light of the COVID-19 pandemic, given the emergent parallels between the two health crises.

\section{TRUST AND CREDIBILITY}

Fundamentally, effective health communication entails trust between the public and the
Summary box

As countries around the world begin to roll out COVID-19 vaccines, vaccine safety communication is more relevant than ever.

- The dengue vaccine controversy in the Philippines offers lessons that can be applied to immunisation programmes being organised today to address the COVID-19 pandemic.

- Effective vaccine safety communication entails (re) building relationships of trust between government and the public, upholding the credibility of scientific institutions and maintaining transparency.

- It also involves viewing health against the broader framework of equity, using an interdisciplinary approach to health communication and putting a premium on public feedback.

scientific community. Building confidence in vaccines 'implies trust in the vaccine (the product), trust in the vaccinator or other health professional (the provider), and trust in those who make the decisions about vaccine provision (the policy-maker) ${ }^{6} .{ }^{6}$ In other words, trust springs from credibility.

One way to do this is through deference to non-partisan, expert institutions and upholding the credibility of these institutions. In the dengue vaccine controversy, this was seen in the involvement of the Philippine General Hospital's independent panel of experts who became the de facto unbiased inquisitors of the sensationalised turn of events. Unfortunately, though their investigation virtually exonerated the vaccine from the deaths of the children, these experts had to compete with many other voices, mostly from government, that only undermined whatever authority they may have held during the crisis.

Under COVID-19, the importance of letting scientific institutions take the lead in communications cannot be overstated. These institutions remain our most credible sources of information; thus, they must lead 
without interference-or perceived interference-from partisan figures. Politicians may help inspire public confidence towards vaccination, but too often they engage in medical populist tropes, such as passing off unfounded knowledge claims as facts, that are damaging to the scientific institutions. ${ }^{34}$ Left unchecked, these political tactics result in 'vaccine messianism', where politicians overemphasise their faith in vaccines, obscuring what the scientific community has actually proven thus far, ${ }^{7}$ And a public that views vaccines as mere political tools being wielded by actors in power, as what transpired during the dengue vaccine controversy, will only end up rejecting a vaccine, no matter how efficacious.

\section{TRANSPARENCY}

Related to trust and credibility is transparency, which entails a consistent effort to disclose necessary information from all parties in any health-related endeavour. This means not just being upfront about factual information-the science of newly manufactured vaccines, their risks and limitations-but also about the circumstances with which they will be given to an anxious public.

The late disclosure of the dengue vaccine's potentially life-threatening effects led to accusations of lack of transparency and widespread speculation that the programme, with its multibillion-peso funding, was in reality railroaded by corrupt practices. ${ }^{8}$ Separately, under COVID-19, violations of this cardinal rule of transparency have already transpired in the Philippines even before public vaccinations have started: in December 2020, it was discovered that no less than members of the Presidential Security Group had been injected with the yet-tobe-approved Sinopharm vaccines, smuggled from China; worse, a black market of illegal vaccinations among Chinese nationals in the country was apparently being tolerated by the government. ${ }^{910}$ These situations, instead of pre-empting feelings of suspicion towards vaccines, only worsen the public's mistrust towards their government and, consequently, towards vaccines themselves.

\section{EQUITY}

Another important tenet is equity-the vulnerable and marginalised on equal footing with the privileged. In the dengue vaccine controversy, a point of inequity was initially raised by politicians who questioned the selection process for the programme's implementation; why, during an election year, certain administrative regions were supposedly 'prioritised' over others. ${ }^{11}$ Subsequently, inequity could be seen in the way local government units-some more resource-rich than others-were forced to intervene in the aftermath of the national communication breakdown.

A year into the COVID-19 pandemic, equity red flags have been raised again and again-from politicians flouting quarantine measures, to these same politicians abusing their authority and disregarding the "prioritisation list' of the vaccination process. ${ }^{12}$ At the same time, news of numerous highly urbanised cities forging their own vaccination deals with international pharmaceuticals have raised fears that such undertakings will result to geographic inequity, with poorer cities and regions at a disadvantage.$^{13}$ Equity in vaccine communication therefore entails looking at vaccination against the broader public health infrastructure, with clear guidelines, audience segmentation and targeted campaigns emphasising-and insisting on-universal access to the vaccines. This will not only streamline COVID-19 vaccinations, but in the long run, even improve coverage rates of existing vaccines.

\section{PARTICIPATION AND FEEDBACK}

Finally, effective health communication means accounting for participation and feedback. As shown by the dengue vaccine controversy, 'expertise' is not enough in the face of insufficient 'buy-in' from all concerned sectors, including within the scientific community.

Participation means recognising that vaccine hesitancy-and vaccine safety communication-involves not just the scientific community but every other institution across political and civil society. Against a predominantly Western framework of science communication, it will entail synchronous, interdisciplinary engagement among: primary care workers who know the situation on the ground (ie, hospital and community settings); social science and communications experts with the necessary tools to understand 'local vaccine culture'the root of people's fears, distrust and (mis)conceptions regarding vaccines, as well as the healthcare system ${ }^{14-16}$; media workers who must ensure that the information being relayed to the public do not get sensationalised or distorted; and even religious and civil society groups with established influence over their communities. Additionally, this will also entail 'starting young'-integrating and emphasising the importance of healthcare communications into the training curricula of hospitals and medical schools. $^{17}$

Most importantly, participatory communication means putting a premium on feedback, showing people that their government is responding to them. With the dengue vaccine controversy, the failure of government to preserve feedback mechanisms led to the rise of 'moral entrepreneurs' who manufactured competing narratives and overwhelmed communication channels, both in mass and social media. ${ }^{4}$

However, feedback can also be a means for authorities to know what the people are thinking-and thinking incorrectly. Under COVID-19, a vigorous feedback mechanism can pre-empt misinformation and disinformation, especially online. ${ }^{18} 19$ This means not just anticipating occasions of fake news but also occasions to be honest to the public regarding vaccine risks and failure. Not only for vaccine communication, but health communications in general, investing in improving feedback mechanisms has become an essential—and life-saving-path forward. 


\section{CONCLUSION}

Vaccine mistrust is not irreversible; a study comparing vaccine confidence before and after the dengue vaccine was administered in the Philippines showed that while confidence levels had indeed plunged, they had also seen a relative, gradual increase, suggesting that attitudes can be swayed over time. ${ }^{20}$

However, as the Philippine experience hopefully makes clear, especially for countries in similar straits, rebuilding trust in vaccines, and the healthcare system, is an arduous road forward, where partnerships between the authorities and the public must be re-established through transparent systems, on top of long-term investments towards the healthcare infrastructure. Politicisation must be avoided at all costs, and credible, non-partisan actors must be at the forefront of communicating the case for immunisation. Checks and balances must always be preserved, which means both the public_-including the medical community - fulfilling its role as active, critical participants of the healthcare system and the government being accountable at all times for all its actionsand inactions. Absent such deliberate efforts, any vaccine produced to stomp the pandemic will only go to waste.

Twitter Gideon Lasco @gideonlasco

Acknowledgements The paper is based on a presentation that first author delivered for a webinar organised by BMJ, Asian Development Bank and Unicef on 22 January 2021.

Contributors GL led, and VGY contributed, in all stages of the writing of the manuscript from conceptualisation to editing.

Funding The authors have not declared a specific grant for this research from any funding agency in the public, commercial or not-for-profit sectors.

Competing interests None declared.

Patient consent for publication Not required.

Provenance and peer review Not commissioned; internally peer reviewed.

Data availability statement All data relevant to the study are included in the article.

Open access This is an open access article distributed in accordance with the Creative Commons Attribution Non Commercial (CC BY-NC 4.0) license, which permits others to distribute, remix, adapt, build upon this work non-commercially, and license their derivative works on different terms, provided the original work is properly cited, appropriate credit is given, any changes made indicated, and the use is non-commercial. See: http://creativecommons.org/licenses/by-nc/4.0/.

ORCID iD

Gideon Lasco http://orcid.org/0000-0002-6402-682X

\section{REFERENCES}

1 Mendoza RU, Valenzuela S, Dayrit M. A crisis of confidence: the case of Dengvaxia in the Philippines. SSRN.

2 Pasteur S. Sanofi updates information on dengue vaccine [Internet]. Lyon, France: Sanofi Pasteur, 2017. Available: https://www.sanofi. com/en/media-room/press-releases/2017/2017-11-29-17-36-30

3 Lasco G, Larson HJ. Medical populism and immunisation programmes: illustrative examples and consequences for public health. Glob Public Health 2020;15:334-44.

4 Lasco G, Curato N. Medical populism. Soc Sci Med 2019;221:1-8.

5 Dayrit MM, Mendoza RU, Valenzuela SA. The importance of effective risk communication and transparency: lessons from the dengue vaccine controversy in the Philippines. J Public Health Policy 2020;41:252-67.

6 Larson HJ, Schulz WS, Tucker JD, et al. Measuring vaccine confidence: introducing a global vaccine confidence index. PLOS Curr 2015;7. doi:10.1371/currents.outbreaks. ce0f6177bc97332602a8e3fe7d7f7cc4. [Epub ahead of print: 25 Feb 2015].

7 Lasco G. The perils of vaccine messianism. Philippine daily Inquirer, 2020. Available: https://opinion.inquirer.net/133294/the-perils-ofvaccine-messianism

8 Roxas PAV. No corruption in Dengvaxia program-Garin. Philippine daily Inquirer, 2018. Available: https://newsinfo.inquirer.net/981932/ no-corruption-in-dengvaxia-program-garin

9 Cabato R. A black market for illegal coronavirus vaccines is thriving in the Philippines. The Washington post, 2021. Available: https:// www.washingtonpost.com/world/asia pacific/vaccine-coronaviruschinese-workers-philippines/2021/01/16/e5126c88-4f09-11eb-a1f5fdaf28cfca90_story.html

10 Rappler.com. Lorenzana: Vaccines used by Duterte security smuggled but 'justified'. Rappler, 2020. Available: https://www rappler.com/nation/lorenzana-vaccines-used-by-duterte-securitysmuggled-but-justified

11 Interaksyon. 'No one objected to Dengvaxia roll-out, I approved it because of rising dengue incidence' - Aquino. Interaksyon, 2017. Available: https://interaksyon.philstar.com/breaking-news/2017/12/ 14/113085/aquino-attends-senate-dengvaxia-hearing/

12 Adel R. From VIP testing to VIP vaccination, Filipinos deplore 'unfair' vaccination of soldiers, Cabinet exec. Interaksyon, 2020. Available: https://interaksyon.philstar.com/trends-spotlights/2020/12/29/ 182783/from-vip-testing-to-vip-vaccination-filipinos-deplore-unfairvaccination-of-soldiers-cabinet-exec/

13 SunStar Manila. Direct vaccine deals by LGUs to promote inequity, group warns, 2021. Available: https://www.sunstar.com.ph/article/ 1885700/Manila/Local-News/Direct-vaccine-deals-by-LGUs-topromote-inequity-group-warns

14 Leslie M, Fadaak R, Davies J, et al. Integrating the social sciences into the COVID-19 response in Alberta, Canada. BMJ Glob Health 2020:5:e002672.

15 Sonekar HB, Ponnaiah M. Emergence of coronavirus (COVID-19) outbreak: anthropological and social science perspectives. Disaster Med Public Health Prep 2020:1-3.

16 White SJ, Barello S, Cao di San Marco E, et al. Critical observations on and suggested ways forward for healthcare communication during COVID-19: pEACH position paper. Patient Educ Couns 2021;104:217-22.

17 Arneja I, Lal P. Communications skills training - a missing link in medical education curriculum. MAMC J Med Sci 2017;3:117-9.

18 Pollett S, Rivers C. Social media and the new world of scientific communication during the COVID-19 pandemic. Clin Infect Dis 2020;71:2184-6.

19 Malecki KMC, Keating JA, Safdar N. Crisis communication and public perception of COVID-19 risk in the era of social media. Clin Infect Dis 2021;72:697-702.

20 Piot $\mathrm{P}$, Larson $\mathrm{HJ}$, O'Brien KL, et al. Immunization: vital progress, unfinished agenda. Nature 2019;575:119-29. 